\title{
Discussion on Improving Marine Boiler Efficiency on Board
}

\author{
Feifei Li \\ Marine Engineering Department, Tianjin Maritime College, Tianjin, 300350, \\ China
}

Keywords: Marine boiler; Do's; Don'ts; Boiler efficiency

\begin{abstract}
Marine boiler is one of the most important systems on board which is used to produce steam to drive the main engines or auxiliary machinery. Steam demand is the main criteria of operating a boiler at a given load for marine boilers. It is of importance that boilers cannot be overloaded to achieve excessive output and ensure all the parameters are within the safety limits. Therefore, some important do's and don'ts must be followed which marine engineers must know on operating a marine boiler in a safe and efficient manner.
\end{abstract}

\section{Introduction}

On modern society, vessels play a critical role in world's transportation and high-modernized and high-automated ships have become the world's trend. Therefore, the advanced technologies are used and advanced devices are provided on board. In addition, researchers are more and more concerning about the environmental protection and resources saving in shipbuilding. With the recent technical development of shipping industry, ships which are capable of reducing energy consumption and enhancing the operation efficiency are more popular all around the world. Marine boiler is such an important application in ship's engine room that needs special attention, considering the fact that it supports several other operations and machinery, including the main engine, auxiliary machinery, etc. Maintaining and improving boiler efficiency requires taking note of a number of factors, for example, following the correct operating procedures, checking associated valves and so on. Researches on improving marine boiler efficiency have been received much more attention in recent years. However, marine boiler may cause severe damage to the safety of property and even to the human's lives if it is operated improperly. Crews on board know that the dangers of high-temperature steam and they must be careful while operating and maintaining the boilers. According to the reference data, one of the main reasons why such vital accident would occur is that the improper operating procedures and ignoring the safety precautions. Each of engineers on board is concerning that all the machinery and systems in engine room can be available and maximize efficiency without potential safety hazard.

\section{Do's and Don'ts for Efficient Boiler Operations on Ships}

Although it is a device which has the simple internal parts arrangement, it requires highest standards of safety precautions and correct operating procedures. In order to obtain the highest efficiency, some do's and don'ts must be paid attention to operate the boiler correctly. Do's and don'ts below are some common ones in boiler operation.

\section{Do's in Boiler Operation}

\section{Operating Procedure}

It must be ensured that engineers should follow correct operating procedures when igniting the boiler from the cold condition. In addition, pre and post purging is very critical for every ignition and the air vent must be kept open when initially firing and shutting down the boiler.

\section{Checking Important Parts and Systems}

To ensure the boiler can function well, a variety of important parts and systems need to be checked, otherwise, accidents may occur and cause damage to the boilers. Engineers should check the smoke from the funnel on every watch to gauge the combustion quality of the boiler. Actions should be taken in the event of abnormal color of smoke. Make sure that various valves and 
dampers, e.g. fuel line valves, steam valves and safety valves, are in good order. Quick-closing valves and safety valves should be correctly operational as well. In addition, one of most important part needs to be examined is the furnace. Check the furnace for refractory deterioration and fuel dripping near the burner assembly. If any defect is found, it should be rectified as soon as possible.

\section{Cleaning and Maintaining}

In order to make the boiler have a good performance, cleaning and maintaining work is necessary. Measures mentioned below are some common ones to improve boiler efficiency. Scum valve should be opened to discharge floating impurities and scum regularly and blow down should be performed once a day to keep the chloride level minimum. Soot blowers should be used to perform blowing soot since it can assist to continue the heat exchanging ability of the boiler tubes. On the other side, soot blowing is a precaution against fire. Lubricating is a good and effective measure in maintaining the boiler so that all the required parts and connections should be lubricated and greased at regular intervals. Besides, steam system in boiler is prone to leakages because of fluctuating steam pressure. It is necessary to attend all the leakages as soon as possible to maintain the efficiency at all times.

\section{Safety Precautions}

For the safety reason, it is essential for the engineers to know the safety measures which mostly described in the company Safety Management System. For example, emergency shut down of the boiler, which is located in the ECR, should be checked whether it is functional or not. Marine boiler is oil-fired, high-pressure device with its own fire fighting apparatus. The crew on board should be aware of application method of local fire extinguisher (foam type). In addition, fire drill needs to be carried out periodically to prevent accidents.

Apart from measures and operations mentioned above, there are other points that need to be paid attention in boiler operation.

\section{Don'ts in Boiler Operation}

\section{Starting Failure}

Never let the inexperienced engineer and untrained operator light up the boiler, especially from the cold condition. If the boiler is started but failed 3 times, trouble should be traced prior to another starting. Important points, e.g. pre and post surging, correct starting operating, should be observed. In addition, abnormal conditions in the boiler should be observed carefully in terms of sound, smoke, flame quality, drum level and other parameters. Any abnormalities are found; correct them as soon as possible.

\section{Avoiding Actions}

Never operate a soot blower when the boiler is at a high load. Never do the blow down excessively since the feed water system will add cool water to the boiler drum which will reduce the thermal efficiency and stress in the boiler. Never operate the boiler at a higher load as a regular practice. Occasionally, boiler can be overloaded because of excess demand; however, frequent overload will lead to high stress and tube failure. Never operate the boiler when there is leakage in any water tube and rectify the failure at the earliest. Never supply sea water in any condition. If the cascade is filled with sea water because of heavy leakage in the condenser, secure the equipment and correct the problem.

\section{Periodic Maintenance}

Watch out the water level at regular intervals instead of relying on the water level indicator which is located in the ECR. Keep a close watch to get the real and clear level by the local glass gauge. Keep the furnace door of the boiler closed in normal condition. The door can be opened to do cleaning and inspection work for the burner or furnace. Once the work is done, the furnace door will be closed. In addition, periodic maintenance work is critical for the boiler and boiler auxiliaries and fittings as the boiler efficiency will be much reduced if the maintenance work is not carried out over a period of time.

The above mentioned do's and don'ts provide a general overview to ensure that boiler efficiency is maintained while the safety aspect is kept intact. 


\section{Suggestions on Improving Boiler Efficiency on Board}

One of the important tasks for marine engineers on board ships is to ensure that all the machinery and systems are running efficiently, especially the critical equipment. The good running conditions depend on a variety of factors which can affect the overall performance and efficiency of these applications. Special attention must be paid to these important parameters for the marine boilers as well. Several important points mention below must be taken into account in order to improve boiler efficiency and performance.

\section{Feed Water Temperature and level}

It is essential to maintain the standard of all the inputs of the boiler system in order to improve the system's efficiency. Feed water system in the boiler system plays an important role in enhancing the boiler operation efficiency. First of all, desired temperature of feed water is required. The optimum temperature is maintained at approx. $80-85^{\circ} \mathrm{C}$ which can ensure the boiler can be worked at a high efficiency. Any decrease in feed water temperature can result in more time for heating up the water to produce steam, more fuel consumption and less overall efficiency. Besides, water level and temperature in the cascade should be monitored carefully as well. Any drop of the level in the cascade should be arouse attention, it indicates more cold water will be added to maintain the correct level, which cause reduction in the feed water temperature.

In summary, feed water temperature is a key factor to improve boiler efficiency. Therefore, feed water temperature should be maintained. Hot well level controller should be operated properly. Feed water temperature in hot well should be monitored.

\section{Supply of Air/ Steam to Burner}

To a large extent, an important factor which can determine the boiler efficiency is the percentage of air/steam. This is required so that sufficient fire is ignited in the furnace through good combustion. For the oil-fired marine boiler with register type burner, $15-20 \%$ by weight of air is required for efficient combustion. Excessive air within the required range may cause reduction losses in the fuel gas. In practice, every $1 \%$ reduction in the excess air supplied to the furnace results in approx. $0.6 \%$ increase in the boiler overall efficiency. In enhancing the efficiency by air/steam, several points should be taken into consideration. Reduce or avoid excess air/steam; be aware of air fuel ratio under the rating; check the content of combustion gases to adjust the air fuel ratio correspondingly. It is better to fit a boiler economizer to improve the boiler efficiency.

\section{Observation of Critical Parameters and Parts}

Marine boiler is a device which maintains high pressure to produce high temperature steam for driving or other purposes. The outer shell or frame of the boiler is a key part since it not only has a lot to do with the pressure but also maintains the flue gas temperature intact inside the boiler to have a good heat exchanging ability. It is therefore necessary to check whether there is leakage from the boiler shell which may be caused by deformation or bulging of shell resulting in cracks. If there are black spots in the outer plates of the boiler, it indicates the boiler shell has cracks and leakages may be occurred. Check the refractory of the boiler to avoid overheating of the shell and damage to it. If there is failure, replace the damage refractory as soon as possible. Check the insulation of the shell to minimize the heat loss and maintain the boiler efficiency.

\section{Necessary Cleaning Work}

Soot deposits will form in the tube and internal surface of the oil-fired boilers which can decrease the heat exchanging effect. It is indicated by the elevated tube stack temperature whether there are soot deposits or not. Every $22^{\circ} \mathrm{C}$ increase in the stack temperature will cause approx. $1 \%$ loss in efficiency and $3 \mathrm{~mm}$ soot formation will cause about $2.5 \%$ fuel consumption increase. Therefore, regular cleaning work and observation of parameters must be carried out to avoid loss of efficiency as much as possible.

Blow down is a very important cleaning work as well to maintain the efficiency and it should be performed at regular intervals. It indicates that such work should be done only when the chloride level is high in the test or high conductivity alarm occurs. However, long period of blow down is avoided since correct chloride and thermal stress should be kept. Regular short blow down and check on chloride in the feed water are recommended. 


\section{Boiler Loading}

Boiler loading should be maintained within a correct range, neither too high nor too low. The optimum range to obtain the highest efficiency is $2 / 3$ of the full load. If it falls below half of the full load, more air is required to burn the fuel which can increase of the heat loss. Therefore, avoid operate the boiler below $25 \%$ load because the efficiency will be much reduced. Keep the load at the $2 / 3$ of the full load.

\section{Conclusion}

Marine boiler is a device that requires a lot of attention to achieve the maximum efficiency. There are a number of measures to achieve the efficiency. In the previous passages, some do's and don'ts and suggestions about boiler efficiency have been discussed. Apart from suggestions above mentioned, it is certain that there are other measures need to be taken. In conclusion, correct operation is the essential step to run the boiler. The operator is required to have the professional knowledge to operate the boiler. Keep a check on the various important parts and systems and do the cleaning and maintaining work play a crucial role in obtaining the boiler efficiency. Feed water temperature and level control, supply air/steam to burner, important parameters and parts and systems, boiler loading, etc. are common factors need to be controlled strictly and carefully. It is therefore necessary for the engineers to do the check and cleaning work according to the instruction manual. During boiler operation, safety precautions need to be taken to avoid potential accidents and hazards.

\section{References}

[1] Cen Kefa. Science of Advanced Combustion [C]. Hangzhou: Zhejiang University Press, 2002. 33-57.

[2] Beltrame, A, Porshnev, P, et al. Soot and NO formation in Methane-Oxygen Enriched Diffusion Flame [J], Combustion and Flame, 2001, 124: 295-310.

[3] Jia Hongxiang. Heat transfer in Boiler Furnace[M]. Xi'an: Xi'an Jiaotong University Press, 1988.

[4] Liu Hongru, Wan Longjun, Xu yiqun. Research On Simulation of Marine Auxiliary Boiler System [J], Mechanical \& Electrical Engineering Technology, 2015, 44(7) 89-91.

[5] Zhao You. Analysis of the Method of Improving the Thermal Efficiency of Marine Auxiliary Boiler [J], Science and Technology \& Innovation, 2015, 13, 144-146.

[6] Yang Zhiyun, Zhou Guoyi,et al. The Experimental System and Analytical Method of the Flue-gas Filter used on a Marine Supercharged Boiler [J], Ship Marine Engineering, 2006, 2, 25-27.

[7] R.S. Virdi, D.G. Thakur. Investigation and Analysis of High Temperature Corrosion and Degradation of Marine Boiler Combustion Swirler [J], Journal of Marine Science and Application, 2016, 15(1) 86-94

[8] Zzhang Lixiang. The Boiler Steam Temperature Fuzzy-adaptation PI Control System Intelligent Control and Automation, 2000. Proceedings of the 3rd World Congress On Volume, July, 2000. 